\title{
A Comparative Study On The Effects Of Market Crisis And Recessions On The Performance Of Defensive Sectors
}

Elikanami Ole-Meiludie, University of Cape Town, South Africa Sizwe Mashinini, University of Cape Town, South Africa

Chun-Sung Huang, University of Cape Town, South Africa

Kanshukan Rajaratnam, University of Cape Town, South Africa

\begin{abstract}
Research has shown that the performance of defensive sectors is consistent during a recession. However, whether such consistency still holds during periods of market crisis, which is considered an economic anomaly, is not immediately obvious. This paper proposes a further investigation into the performance of defensive sectors during a market crisis, particularly on the Johannesburg Stock Exchange (JSE). It will investigate whether these defensive sectors retained their noncyclical nature during the recent market crisis (01/12/2007 - 31/08/2009) by comparing their performance during the crisis to their performance in South Africa's most recent recession (1/12/1996 - 31/08/1999). Our investigation is carried out by assessing the betas of these sectors across both periods of focus. It then adds to the assessment of the betas by comparing the variances of the defensive sectors in both periods to determine whether there is a statistically significant difference. Our study is unique in that it proposes to investigate with the different market capitalisations (large, medium, and small) across the defensive sectors. The results of this study give conclusive evidence that defensive sectors do indeed remain non-cyclical during a market crisis. We can therefore give recommendations on switching to defensive strategies with greater certainty of the performance of defensive sectors during this economic anomaly.
\end{abstract}

Keywords: Market Crisis; Defensive Sectors; Recession

\section{INTRODUCTION}

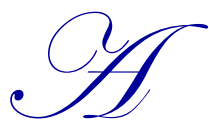

ccording to both international and local studies there is contradiction as to whether the performance of these defensive sectors was consistent or not during the recent market crisis. In light of this, the aim of this study is to verify whether defensive sectors in South Africa maintained their non-cyclical behaviour during the market crisis, given that defensive sectors are defined to be sectors that are not sensitive to the market's movements. This paper is unique because it interrogates the performance of defensive sectors by breaking down their performances into the different market capitalisations that make up the sectors. The main contribution lies in the motivation it provides for the use of a defensive strategy in an investor's portfolio during a market crisis, which is considered an economic anomaly. We achieve this by providing evidence for the consistent performance of defensive sectors during a market crisis.

This study will be laid out in the following way. Section 2 defines the technical terms, which will be used throughout the study. It also compiles and contrasts prior local and international studies on this topic. Section 3 will cover the methodology used to execute the analyses on the betas and the variance in the sector returns for the recession and market crisis periods. Results obtained from the analysis of the betas and the variance in the sector returns are elaborated in Section 4. Section 5 then provides practical recommendations on the application of this study's findings in investors' portfolios. Finally, we conclude our findings and recommendations of this paper in Section 6. 


\section{PRIOR LITERATURE}

This section provides a detailed description of the technical terms that will be used throughout the paper and provides an overview of the findings in both local and international studies. In addition, it provides further grounds and justifications for our study.

Over the years, and through observing their historical performance, defensive sectors have come to be defined as those sectors that have a 'historic beta of less than 1' (Davis \& Philips, 2007). This implies that defensive sectors are less sensitive to risk factors that cause variations in the market. Some studies define defensive sectors as having both its one and 12-month betas less than 0.6 (Levy, 1984). Due to their low betas, defensive sectors are known to remain relatively stable as it moves through different business cycles (bull markets and bear markets). Hence, they are also known as non-cyclical sectors as opposed to cyclical sectors that are sensitive to market movements (Arguile, 2012). Defensive sectors should outperform the market during a recession or a bear run, but are likely to underperform the market during a bull run (Davis \& Philips, 2007).

This study analyses the behaviour of consumer goods, healthcare, and consumer services as mentioned in Arguile (2012). These sectors are considered defensive because they are relatively price inelastic towards demand since becoming necessities of modern-day life (Yoon, 2012). In the healthcare industry, pharmaceuticals are highly regulated by government so as to cap prices, thus keeping demand at a constant level. Furthermore, competition is relatively high in this sub-sector as the expiration of patents allows generic products to increase competition which brings prices down in the industry (Yoon, 2012). In the consumer goods sector, some goods are part of people's staple diet (Goodspeed, 2009). They therefore need to be consumed regardless of one's disposable income. Goods such as alcoholic beverages are often consumed in the same amounts even though the taxes on them are increased annually. The demand for such products is therefore not affected by a recession. In fact, demand may even increase during these times of increased stress (Waxler, 2004).

In economics, a recession is defined as a period of gradual but significant decline in economic activities which lasts longer than a few months. Generally a recession is observed in two consecutive quarters of negative economic growth. Honkapohja (2009) defines a market crisis as a period of sudden decline in financial assets or institutions' value. In theory, there are three main types of market crises, namely the banking crisis, currency crisis, and speculative bubble (Honkapohja, 2009). The market crisis observed in 2008 was a result of a burst of the speculative U.S. housing bubble, otherwise known as the sub-prime market crisis (Canstar Research, 2012).

The topic of defensive sectors has not been thoroughly covered in the existing literature. This may be attributed to the fact that their behaviour is defined as constant and non-cyclical, unlike other more 'aggressive sectors' whose nature is significantly more complicated (Levy, 1984). Surprisingly, even less research has been done with regards to the behaviour of defensive sectors during the recent market crisis. Prior research that analysed the behaviour of defensive sectors, both in general and during the market crisis, were inconclusive and presented conflicting views.

Bellehemeur's (2008) study, conducted on the U.S. stock market, offers an international perspective with regards to the behaviour of defensive sectors during the market crisis. By constructing six portfolios, whereby each represents a different defensive sector in the U.S. market, Bellehemeur (2008) provides a sample of the characteristics of defensive sectors in the U.S. market for the period between December 2007 and August 2008. It should also be noted that some of these sectors are also defensive sectors in the South African market. This gives an indication as to how the counterpart defensive sectors in the South African market should have behaved during the market crisis. The mean returns for each defensive sector which included large capped pharmaceuticals, utilities, household goods, food companies, fast food giants, and drug retailers were compared to the return of the S\&P 500 (Bellehumeur, 2008). As expected all of the defensive sector mean returns during the market crisis were above that of the S\&P 500's. This provides evidence, in the international arena, that defensive sectors behaved in a non-cyclical manner by outperforming the S\&P 500 when markets were down during the market crisis.

Further evidence based on the research conducted by Levy (1984) on the U.S. market indicate that defensive sectors should maintain their non-cyclical behaviour as they exhibit betas which are less than 1 . The 
results of this study show that the 1-month and 12-month betas of defensive sectors are less than 0.6. However, the average betas decrease when increasing the time horizon on which they are measured (Levy, 1984). The study provides evidence that the defensive sectors are more likely than not to outperform the market during a crisis given that their betas are not likely to increase to greater than 1. In Davis and Philips (2007), the U.S. utilities, consumer staples and healthcare sectors were all observed to consistently have higher mean excess returns than the cyclical sectors.

A similar study, to that of Bellehemeur (2008), was conducted in the South African market by Arguile (2012) to analyse the behaviour of defensive sectors on the JSE during the market crisis. The findings of Arguile's study were, however, different to Bellehemeur's in that some of the traditional defensive sectors on the JSE, which have a historical beta of less than 1, did not behave in a non-cyclical manner. These traditional defensive sectors are healthcare, consumer goods, and telecommunications. It could be argued that this is the case because Arguile's (2012) study was more thorough since it made use of more than one metric to asses the behaviour of defensive sectors. These metrics included beta's generated by using the CAPM approach, daily mean returns, GARCH volatility measures and a volatility ratio. Statistical data metrics were used to compare the performance of the traditional defensive sectors between two periods, before the market crisis and during the market crisis. This was compared to the performance of other cyclical sectors, as well as the All Share Index (ALSI) during these two periods. The study found that the traditional defensive sectors performed inconsistently based on all three metrics. Based on the mean return metric, all three defensive sectors outperformed the ALSI during the market crisis. Based on volatility, however, only healthcare and consumer goods outperformed the ALSI, and on the beta metric only the healthcare sector outperformed the ALSI (Arguile, 2012).

A parallel line of research is the practical application of defensive strategies on portfolio management. The implementation of these strategies entails predicting when the market is going to decline. There are a number of indicators used in practice in order to predict whether the market is about to enter into a recession, a bear market or possibly a market crisis. Davis and Philips (2007) makes use of an inverted U.S. Treasury yield curve to signal an imminent downturn in the market. The study also makes use of P/E ratios and market returns. It shows that if the current $\mathrm{P} / \mathrm{E}$ ratio is at least 2 standard deviations above the historical forward P/E ratio then the markets are deemed overvalued and may start to decline. An alternative method used in practice is that if the 12-month market returns drop by at least $5 \%$ the market is likely to enter into a recession or bear market (Sassetti \& Tani, 2006).

Although the above-mentioned indicators do not time the market to perfection, once a decline in the market has been identified investors are able to reduce their losses for the duration of the recession or bear market (Sassetti \& Tani, 2006) by weighting defensive sectors more in their portfolios. The results for these studies show that a market timing strategy which incorporates a defensive strategy is not successful, nor is it reliable as the excess returns produced by these strategies are statistically insignificant and sometimes negative (Davis \& Philips, 2007). This is partly because of the inconsistent performance of certain defensive sectors over time (Davis \& Philips, 2007).

\section{METHODOLOGY}

This section discusses the procedures used to execute the analyses on the betas and the variance in the sector returns across both periods. Each sector is divided into the Top 40 which represents Large Market Capitalisation Sectors (large cap), the Middle Market Capitalisation Sectors (mid cap), and Small Market Capitalisation Sectors (small cap) using the existing JSE indices as per the methodology used in Kruger, Rajaratnam, and Huang (2012). This is done in order to analyse the nature of defensive sectors in more detail, as well as to differentiate our study from prior research (see Table 1 for the list of stocks analysed).

This paper will use the Capital Asset Pricing Model (CAPM) to observe and analyse stock betas. These stock betas will be aggregated and averaged in order to obtain the corresponding sector betas. Fundamentally, CAPM bases stock returns on (a) the time value of money, otherwise known as the risk free rate, $R_{f}$; and (b) a risk measure beta, $\beta_{\mathrm{i}}$, that measures the extent to which stock returns and the market (ALSI) co-vary, and a market risk premium $\left(R_{m}-R_{f}\right)$, where $R_{m}$ represents the historical market return. An alternative to CAPM is the Arbitrage Pricing Theory (APT). The two methods differ mainly in the modelling of the assumed risk as a measure of market variation. 
A one-sample variance test is utilised in this study to supplement the observations made from the betas of defensive and cyclical sectors during the recession and market crisis. In particular, the variance test compares the variance in returns of the sectors during the recession to the variance in returns during the market crisis. The difference in variances is assessed on a market cap level; i.e., large cap, mid cap, and small cap, for both defensive and cyclical sectors.

The one-sample variance test was executed based on the following hypothesis:

$\mathbf{H}_{0}: \quad \sigma_{\text {crisis }}^{2}=\sigma_{\text {recession }}^{2}$

$\mathbf{H}_{\mathbf{1}}: \quad \sigma_{\text {crisis }}^{2}<\sigma_{\text {recession }}^{2}$ or $\sigma_{\text {crisis }}^{2}>\sigma_{\text {recession }}^{2}$

Where $\sigma_{\text {crisis }}^{2}$ refers to the variance in returns over the crisis period and $\sigma_{\text {recession }}^{2}$ the variance in returns during the recession period.

\section{a. Time Series Data}

The nature of stock returns follows a time series which is different to cross-sectional data used in most regression analyses. Observations of time series data are correlated across time, whereas in cross-sectional data observations are independent. In other words, such observations cannot be assumed independent. An observation from $X_{t}$ is affected by a prior observation $X_{t-1}$, where $t$ indicates the current time period and $t-1$ the previous (Wooldridge, 2009). The following time series assumptions are also tested to ensure that the estimators for beta used in this study are unbiased, thus making the data appropriate for Ordinary Least Squares (OLS) regression (Wooldridge, 2009).

Table 1: Stock List

\begin{tabular}{|l|l|}
\hline Ticker & Name of the Stock \\
\hline ACL & Arcel \\
\hline AFE & AECI Limited \\
\hline AFR & Afgri LTD \\
\hline AFX & African Oxygen Limited \\
\hline AGL & Anglo America plc \\
\hline AMS & Anglo Platinum \\
\hline ANG & AngloGold Ashanti \\
\hline APN & Aspen Pharmacycare Holdings LTD \\
\hline ARI & African Rainbow Mining \\
\hline AVI & Avi-LTD \\
\hline CFR & Compagnie Richmond \\
\hline CLH & City Lodge Hotels LTD \\
\hline CLS & Clikcs Group LTD \\
\hline CSB & Cashbuild LTD \\
\hline DRD & DRD Gold LTD \\
\hline FBR & Famous brands LTD \\
\hline HAR & Harmony GM Co LTD \\
\hline ILV & Illovo Sugar LTD \\
\hline IMP & Impala Platinum Holdings LTD \\
\hline IPL & Imperial Holdings LTD \\
\hline JDG & JD Group \\
\hline KGM & Kagiso Media LTD \\
\hline LON & Lonmini PLC \\
\hline MDC & Mediclinic Internat LTD \\
\hline MPC & Mr Price Group LTD \\
\hline MRF & Merafe Resources LTD \\
\hline MTN & MTN \\
\hline NHM & Northam Platinum LTD \\
\hline NPN & Naspers LTD \\
\hline OMN & Omnia Holdings LTD \\
\hline & \\
\hline & \\
\hline
\end{tabular}


Table 1 cont.

\begin{tabular}{|l|l|}
\hline PAM & Palabora Mining Co LTD \\
\hline PIK & Pik n Pay Stores LTD \\
\hline RBW & Rainbow Chicken LTD \\
\hline SAB & SAB Miller plc \\
\hline SAP & Sappi LTD \\
\hline SHF & Steinhoff Holdings LTD \\
\hline SHF & Steinhoff Holdings LTD \\
\hline SHP & Shoprite Holdings LTD \\
\hline SUI & Sun International LTD \\
\hline TBS & Tiger brands LTD \\
\hline TFG & Foschini Group LTD \\
\hline TRU & Truworths International LTD \\
\hline WHL & Woolworths Holdings LTD \\
\hline
\end{tabular}

\section{b. Time Series Assumption 1: Linearity}

Formally, our simple linear regression model is defined as:

Stockreturn $_{\mathrm{t}}=\beta_{0}+\beta_{\mathrm{t}}$ ALSIreturn $_{\mathrm{t}}+\mathrm{u}_{\mathrm{t}}$

where $\beta_{\mathrm{t}}$ is the parameter that captures the relationship between the stock's returns and the market's returns at a particular time period. Fundamentally, it is essential that the linearity of the regression model holds such that the data to be modelled follows a linear relationship (Wooldridge, 2009). To ensure linearity, we assess each beta coefficient from the regression output and investigate whether the p-value of the t-test is significant at a $5 \%$ level of significance using the following hypothesis:

$\mathbf{H}_{\mathbf{0}}: \quad \beta_{\mathrm{t}}=0$

$\mathbf{H}_{1}: \quad \beta_{\mathrm{t}} \neq 0$

The resulting p-value is rejected at a 5\% level of significance for all sectors across both recession and crisis period. Therefore, we conclude that the data is linear in its parameters and follows a linear relationship.

\section{c. Time Series Assumption 2: Weak Dependence}

To make use of the Central Limit Theorem, the large sample properties of OLS must hold. However, in order for such properties to hold, the observations in the data must be independent. Since this is not a realistic condition for time series data, according to its characteristics, the assumption of weak dependence between data will therefore suffice and replace the assumption of independence (Wooldridge, 2009).

Weak dependence assesses how correlated a variable is to itself over time. Intuitively, this allows one to determine how independent the observations of a variable are to each other over time. This can be written as: $\operatorname{Corr}\left(\mathrm{X}_{\mathrm{t}}, \mathrm{X}_{\mathrm{t}+\mathrm{h}}\right) \rightarrow 0$ as $\mathrm{h} \rightarrow \infty$, as seen in Wooldridge (2009), where $\mathrm{X}_{\mathrm{t}}$ is an observation in the current time period and $\mathrm{X}_{\mathrm{t}+\mathrm{h}}$ is an observation in the next time period. This condition therefore allows for the substitution of the independence assumption with the weak dependence assumption for the application of the Central Limit Theorem.

We deploy a scatter plot to analyse whether the stock returns used in the time series analysis exhibits signs of weak dependence. Residuals from the fitted model of ASLI and stock returns are plotted against time. The scatter plots shown in Figure 1 show that residuals are spread around zero, which exhibits an expected value of zero over time (without any loss of generality). This demonstrates that there is indeed weak dependence in the data.

\section{d. Time Series Assumption 3: Zero Conditional Mean}

The zero conditional mean assumption holds when the error terms are themselves independent of the independent variable, ALSI, across all time periods $t$; i.e., $\operatorname{Corr}\left(\mathrm{X}_{\mathrm{t}}, \mathrm{u}_{\mathrm{t}}\right)=0$, where $\mathrm{X}_{\mathrm{t}}$ and $\mathrm{u}_{\mathrm{t}}$ are the observation and error term in the current time period, respectively (Wooldridge, 2009). 
This study made use of a scatter plot to evaluate the relationship between residuals from the model and the ALSI returns (the independent variable). Furthermore, a line of best fit has also been fitted across the scatter plot (see Figure 2). It may also be observed that all lines of best fit are horizontal with zero slope, which indicates that there is no relationship between the ALSI and the residuals in the model. Hence, Figure 2 demonstrates that the average value of the residuals is not related to the ALSI across all time periods. This also ensures that there are no variables which are unaccounted for in the residuals that may be related to the ALSI (Wooldridge, 2009).

The above assumptions are required to hold in order to prove that the estimators for the resulting betas are unbiased. It should also be noted that the assumption for no perfect collinearity, which identifies perfect correlation between multiple independent variables, was not tested for since our study do not include multivariate regression.

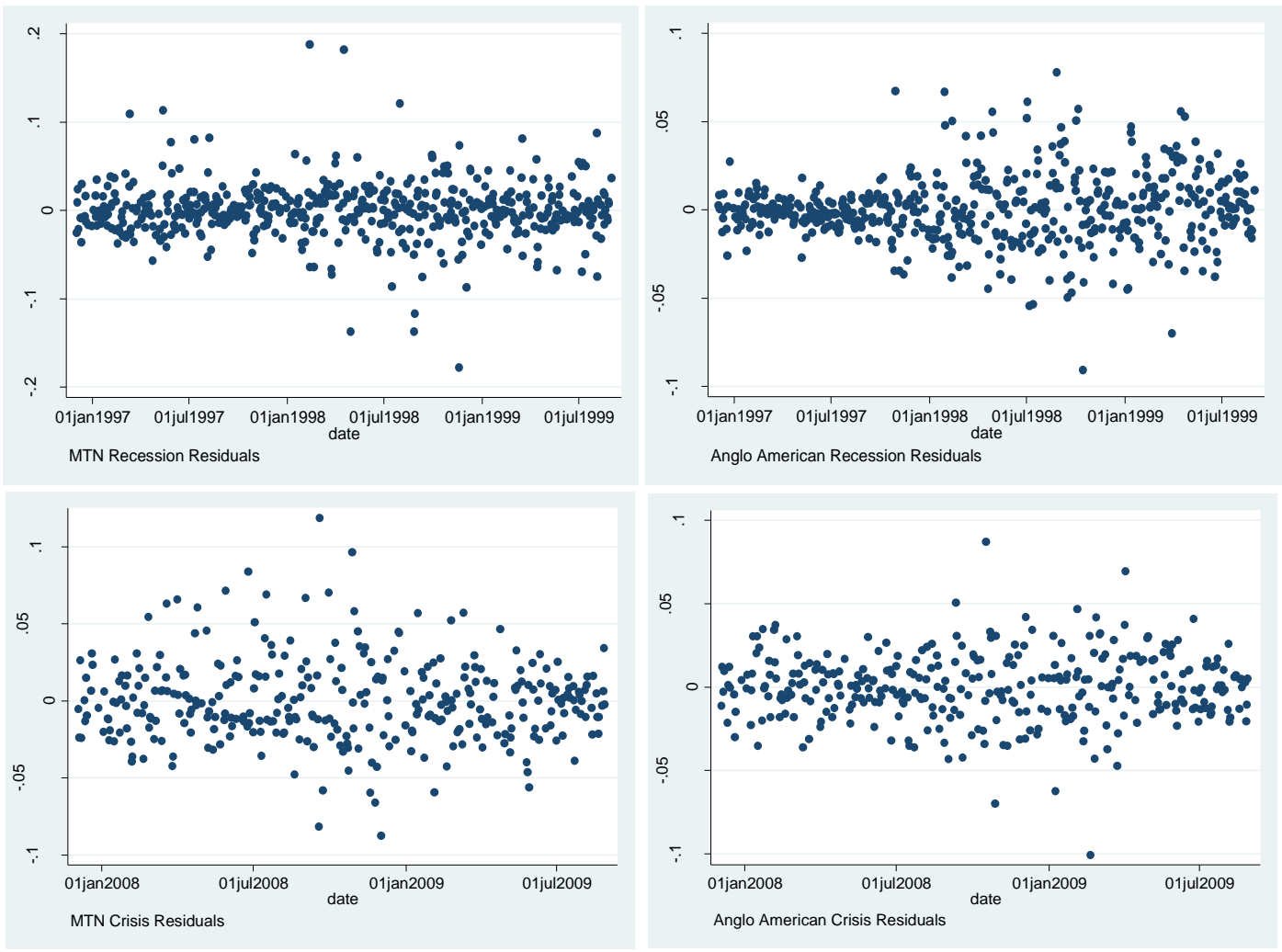

Figure 1: Weak Dependence Data Test
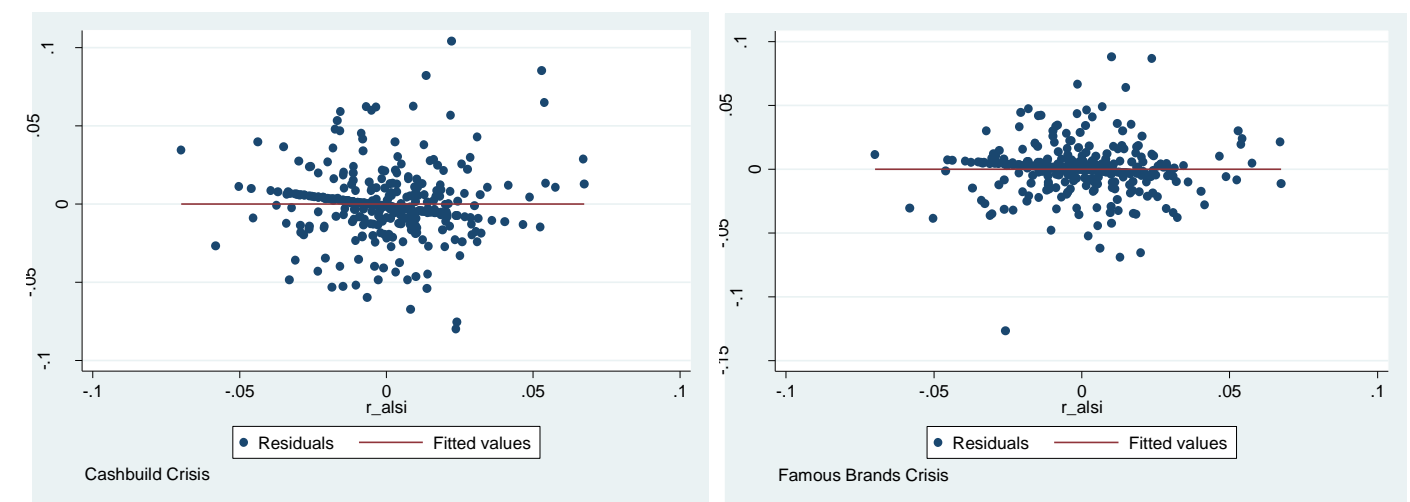

Figure 2: Zero Conditional Mean Data 

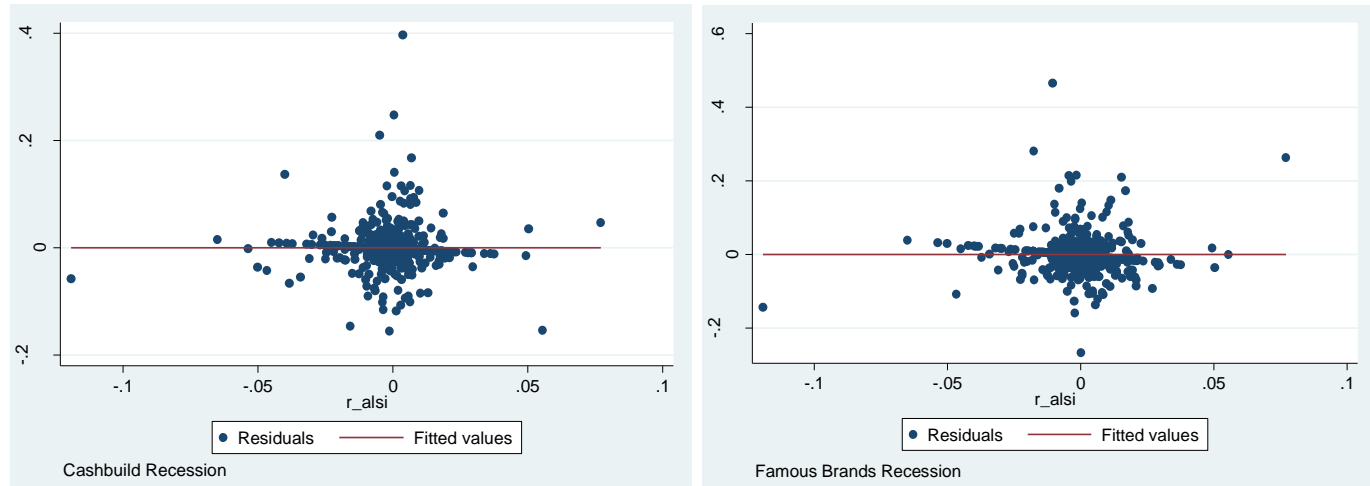

Figure 2 cont.

\section{DISCUSSION OF RESULTS}

When evaluated according to the betas obtained in our analyses, the results show that there is no significant difference between the performance of defensive and cyclical sectors during the recession period. During the crisis period, only the large cap basic material sector produced a beta that was greater than 1, despite the presence of other cyclical sectors. This may have been due to shortcomings in our dataset which are outlined in Section 6. Significant trends, however, were observed in Figure 3, between sectors that were classified as defensive and those that were classified as cyclical. Such trends were extrapolated on in this paper to make observations that may be of use to the investment world.

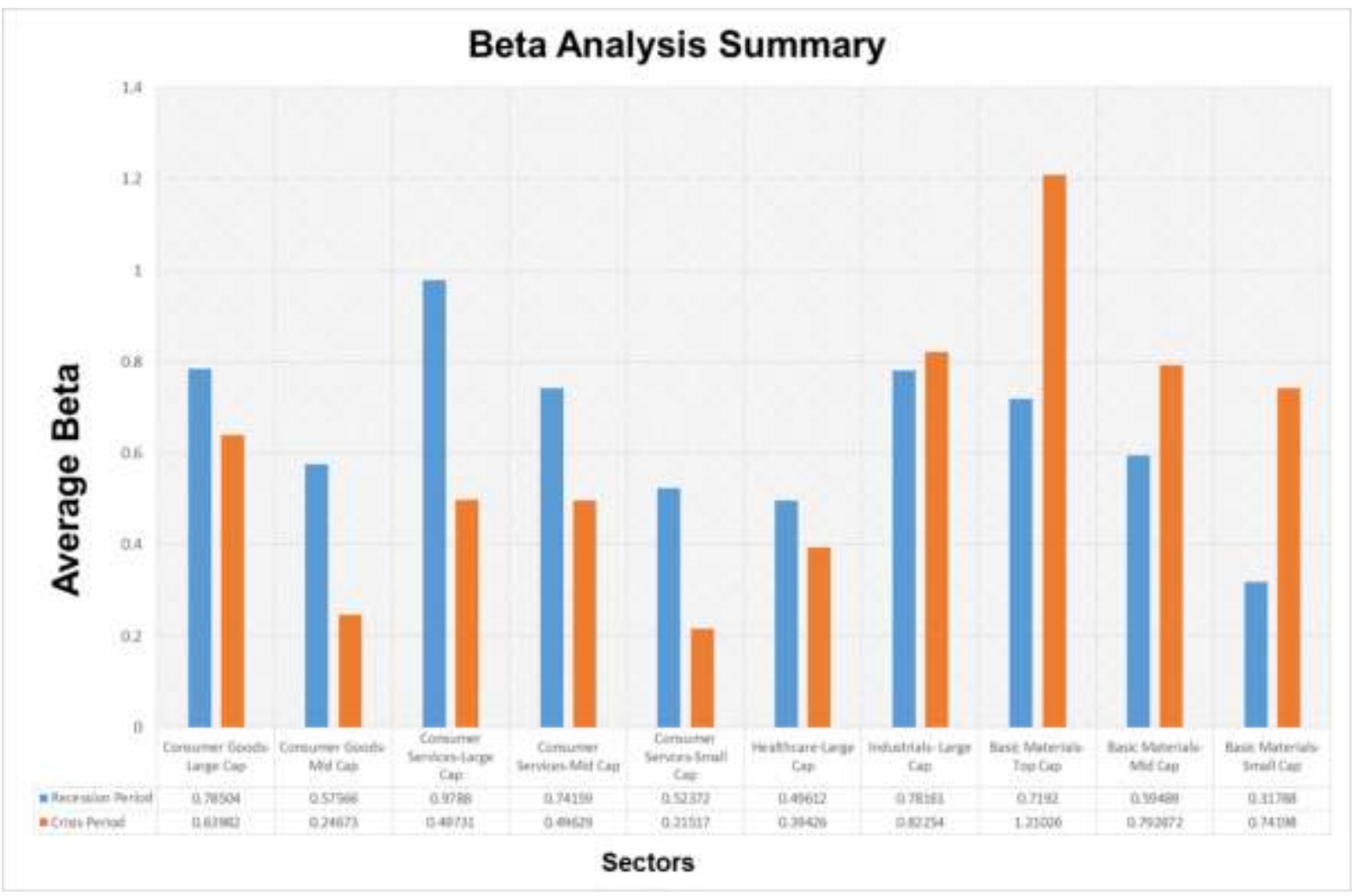

Figure 3: Summary of the Sector Betas

The following trends were evident from the data: Sectors that were classified as defensive during the base period (recession) became less sensitive to the market during the crisis period. In other words, their corresponding 
betas decreased during the market crisis. However, sectors that were classified as cyclical during the recession became even more sensitive to the market's movements during this period of time. This is evident from the significant increase in their corresponding betas. Both the above-mentioned trends were consistent across all three caps within each sector.

A recession is considered a usual part of the cycle that an economy follows (Cao, Ezrati, \& Gambera, 2012). Since there exists an inverse relationship between stock prices and the interest rates set by the South African Reserve bank (SARB), the SARB would typically lower interest rates by pushing more money into the economy. This stimulates consumption in the economy and increases demand for equities with higher returns as opposed to bank deposits with lower returns as a result of low interest rates (Mangani, 2009).

According to Cao, Ezrati, and Gambera (2012) there is often a significant switch of cash flows from cyclical sectors and long-term government bonds to short-term securities and sectors which perform consistently. These sectors tend to be sectors that are classified as defensive. During a market crisis, such a switch would have been heightened since the security given by a steady cash flow at the time would have seemed greater in a time of global uncertainty (Cao, Ezrati, \& Gambera, 2012). Furthermore, during a market crisis one would expect the entire market to decrease in value, but irrationality affects investors' expectations as they flock to buy defensive sector stocks which, in real terms, may also experience losses.

When betas are categorised by market capitalisation, a general trend is observed such that, on average, regardless of sector or market conditions, betas decrease as one moves from large cap sectors to small cap sectors. Empirically, it suggests that, on average, the lower the market capitalisation the more pronounced the characteristics for defensive sectors are. Furthermore, when sectors are observed individually, evidence suggests that a number of small cap sectors exhibit lower than average betas. Statistically, this shows that the estimated regression line is inadequate in its function of explaining the sample distribution. Theoretically, it suggests that the market proxy (ALSI) is constrained at capturing variation in small cap sectors.

Typically, there are about 350 companies listed on the JSE, the ALSI only comprises of the largest 160 companies. Although these companies represent $99 \%$ of the total market capitalisation on the exchange, the ALSI is still found to be highly concentrated (Raubenheimer, 2012). Raubenheimer (2012) also indicated that more than $20 \%$ of the ALSI's weighting comprises of the two largest resource mining companies. Furthermore, the five largest companies on the exchange make up approximately $40 \%$ of the index. Ward and Muller (2012) found that companies falling outside the ALSI are usually considered to be too small, and therefore too illiquid for most investors, which resulted in their exclusion from the index. Strugnell, Gilbert, and Kruger (2011) showed that a number of other share characteristics (i.e., anomalies) such as the size effect and price-earnings are correlated to betas. It was then established by Ward and Muller (2012) that small cap sectors have lower betas than their large and mid cap counterparts. Furthermore, it was discovered that low betas also relate to issues around liquidity, rendering concentration and liquidity constraints to be the two main factors associated with the observation of low betas. This therefore limits ALSI in its role at capturing variation in the small caps.

Table 2: A Summary of the One-Sample Variance Test

\begin{tabular}{|c|c|c|c|}
\hline & Sectors & Observed Beta & Observed Variance \\
\hline \multirow{6}{*}{ } & Large Cap Consumer Services & $\beta_{\text {crisis }}<\beta_{\text {recession }}$ & $\sigma_{\text {crisis }}^{2}<\sigma_{\text {recession }}^{2}$ \\
\hline & Large Cap Health Care & $\beta_{\text {crisis }}<\beta_{\text {recession }}$ & $\sigma_{\text {crisis }}^{2}<\sigma_{\text {recession }}^{2}$ \\
\hline & Large Cap Consumer Goods** & $\beta_{\text {crisis }}<\beta_{\text {recession }}$ & $\sigma_{\text {crisis }}^{2}>\sigma_{\text {recession }}^{2}$ \\
\hline & Mid Cap Consumer Goods & $\beta_{\text {crisis }}<\beta_{\text {recession }}$ & $\sigma_{\text {crisis }}^{2}<\sigma_{\text {recession }}^{2}$ \\
\hline & Mid Cap Consumer Services & $\beta_{\text {crisis }}<\beta_{\text {recession }}$ & $\sigma_{\text {crisis }}^{2}<\sigma_{\text {recession }}^{2}$ \\
\hline & Small Cap Consumer Services & $\beta_{\text {crisis }}<\beta_{\text {recession }}$ & $\sigma_{\text {crisis }}^{2}<\sigma_{\text {recession }}^{2}$ \\
\hline \multirow{4}{*}{ 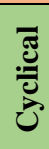 } & Large Cap Basic Materials & $\beta_{\text {crisis }}>\beta_{\text {recession }}$ & $\sigma_{\text {crisis }}^{2}>\sigma_{\text {recession }}^{2}$ \\
\hline & Large Cap Industrials & $\beta_{\text {crisis }}>\beta_{\text {recession }}$ & $\sigma_{\text {crisis }}^{2}>\sigma_{\text {recession }}^{2}$ \\
\hline & Mid Cap Basic Materials & $\beta_{\text {crisis }}>\beta_{\text {recession }}$ & $\sigma_{\text {crisis }}^{2}>\sigma_{\text {recession }}^{2}$ \\
\hline & Small Cap Basic Materials** & $\beta_{\text {crisis }}>\beta_{\text {recession }}$ & $\sigma_{\text {crisis }}^{2}<\sigma_{\text {recession }}^{2}$ \\
\hline
\end{tabular}

Our statistical tests on the variance are conducted with a 5\% level of significance. Any p-value less than $5 \%$ implies that there is significant evidence to prove that either the variance in the crisis returns is less than that of 
the recession period, or that the variance in the crisis returns is greater than that of the recession period. In contrast, p-value greater than $5 \%$ suggests that there is no significant difference in the variance for the two periods. The results in Table 2 above, obtained from the one-sample variance test, supplemented the observations that were made in the beta analysis. These results illustrates that there is a trend between defensive and cyclical sectors. In particular, the trend observed in the beta analysis shows that during a market crisis the betas of the defensive sectors decrease, while those of the cyclical sectors increase relative to their corresponding recession betas. The variance test supported this trend by showing that the variance of defensive sectors decreases during a market crisis, while the variance of cyclical sectors is shown to increase during a market crisis relative to the recession period. An increase in variance implies greater risk within that particular sector, while a decrease in variance implies less risk. We conclude from our observations that cyclical sectors become riskier investments during the market crisis relative to the recession period, while defensive sectors become less risky investments relative to the recession period. Both trends from the beta analysis and variance test suggest that there is a correlation between a decrease in a defensive sector's beta and a decrease in its variance during a market crisis relative to the recession period. Our study also shows that there is a correlation between an increase in a cyclical sector's beta and an increase in its variance during a market crisis relative to the recession period.

However, it should be noted that two exceptions were observed in our study. Large cap consumer goods, which is a defensive sector, was observed to have a higher variance in the crisis period relative to its variance during the recession period. Furthermore, small cap basic materials, a cyclical sector, was observed to have a lower variance in the crisis period relative to its variance during the recession period. For large cap consumer goods, the observation was affected by the presence of Steinhoff, a stock which is also present in the cyclical industrial sector. For small cap basic materials, however, there is no conclusive evidence to clarify why the observation made was contrary to the trend observed for cyclical stocks.

\section{PRACTICAL APPLICATION}

This section provides recommendations on how the findings from this study may be incorporated into investors' portfolios. Firstly, the results of our study provide greater certainty on the performance of defensive sectors on the JSE during a market crisis. Such findings contribute to the existing literature by providing insight into an area that had contradicting views based on prior research. In essence, prior researches have shown that market timing strategies have insufficient predictive power. Our findings can therefore be used alternatively to mitigate an investor's losses once they are in a market crisis. With this knowledge, one can implement a defensive strategy as one would in a recession with more certainty that defensive sectors will perform as they should during a market crisis.

The most apparent trend in our results suggest that it would be advisable for an investor on the JSE to switch to a defensive strategy during a market crisis; i.e., shifting more portfolio weight into defensive sectors. The results show that, during a market crisis, defensive sectors become less sensitive to the market's movements. This is illustrated by a decrease in the beta from recession to market crisis. Our results also shows that during a market crisis, defensive sectors become less risky relative to their riskiness during a recession, this is evident by a decrease in the variance. Which also implies that, on average, a decrease in market returns, due to overreactions from uncertainty in the market, will have a smaller negative impact on an investor's capital. Cyclical sectors on the other hand, become more sensitive to market returns and riskier during a market crisis relative to a recession period. The effects of these movements should be mitigated in an investor's portfolio.

The less obvious trend observed in our study shows that the betas across all sectors decreases as the market cap decreases, due to concentration effects. It is therefore recommended that if an investor is to pursue a defensive strategy they should favour investment in smaller cap defensive sectors to gain more exposure to the non-cyclical nature of defensive sectors. If an investor does not wish to pursue a defensive strategy, or perhaps wants to speculate on a probable future upturn in the market, then we recommend investments in small cap cyclical sectors. Such an investment choice allows for mitigation of the adverse effects of having cyclical sectors during a market crisis. This is also the case since these sectors feature far less in the concentration exhibited on the JSE. The illiquidity presented by these sectors also implies that an investor's capital should decrease at a decreasing rate since it would take other investors longer to trade out of positions in these sectors. 


\section{CONCLUDING REMARKS}

This paper examines the effects of a market crisis on defensive sectors using a recession as a benchmark period. These effects were investigated across different market caps; namely, large caps, mid caps, and small cap. In particular, we look specifically at consumer goods, consumer services, and health care as representative of defensive sectors. In addition, basic materials and industrials were chosen to represent the comparative cyclical sectors.

Evidence from our regression analyses suggests a number of interesting findings. On average, defensive sector betas decrease in the crisis period relative to the recession period. This implies that in a market crisis, on average, defensive sectors exhibit enhanced non-cyclical characteristics; i.e., they are less sensitive to movements on the exchange. However, this is in contrast to the cyclical sectors which, on average, showed signs of increasing betas in the market crisis period relative to the recession. This trend was also observed across different market caps. In addition, both defensive and cyclical sectors' average betas decrease as market cap decreases. This is also partially attributed to the capital concentration found on the exchange. A test on variance across both periods was also conducted to support the resulting beta observations. It was observed that there is a correlation between a decrease in a defensive sector's beta and a decrease in its variance during a market crisis relative to the recession period. There is also a correlation between an increase in a cyclical sector's beta and an increase in its variance during a market crisis relative to the recession period.

Formally, this study finds that defensive sectors become more defensive, as per the definition, in the crisis period. However, the trends observed may only proof useful to investors if they are willing to restructure their portfolios to suit a 'defence strategy' during a market crisis. Further research could investigate the plausibility of using a two-factor APT model as it addresses the issue of offshore investments (van Rensburg, 2002), or looking at longer sample periods or less concentrated stock exchanges.

\section{AUTHOR INFORMATION}

Elikanami Ole-Meiludie is a student of Bachelor of Business Science, specialising in the field of Finance at the University of Cape Town. This work forms part of his and Mr. Mashinini's fourth-year finance research project. Email: olmeli001@ myuct.ac.za

Sizwe Mashinini is a student of Bachelor of Business Science, specialising in the field of Finance at the University of Cape Town. This work forms part of his and Mr. Ole-Meiludie's fourth-year finance research project. E-mail: mshsiz002@myuct.ac.za

Chun-Sung Huang is a lecturer in Finance and an associate of the African Collaboration for Quantitative Finance and Risk Research (ACQuFRR) at the University of Cape Town, South Africa. His research interests lie in volatility modelling and forecasting, time series modelling, Value-at-Risk (VaR) models, and derivatives pricing in incomplete markets. E-mail: Chun-Sung.Huang@uct.ac.za

Kanshukan Rajaratnam is a Senior Lecturer of Finance and an associate of the African Collaboration for Quantitative Finance and Risk Research (ACQuFRR) at the University of Cape Town, South Africa. His research interests lie in decision-making in consumer credit loans, modelling credit union behaviour, and the Basel Accord. $\mathrm{He}$ is a member of the Operations Research Society of South Africa (ORSSA). E-mail: kanshukan.rajaratnam@uct.ac.za (Corresponding author)

\section{REFERENCES}

1. Arguile, W. (2012). Performance of defensive shares on the JSE during financial crisis: Evidence from analysis of returns and volatility (pp. 1-74).

2. Bellehumeur, L. (2008). How have 'traditional defensive sectors' done in this downturn?: Seeking Alpha. [Online]. Retrieved 2013, April 19 from http://seekingalpha.com/article/90129-how-have-traditionaldefensive-Sectors-done-in-this-downturn

3. Canstar Research. (2012). Global financial crisis - What caused it and how the world responded? 
4. Cao, B., Ezrati, M., \& Gambera, M. (2012). Understanding the business cycle. In CFA programme curriculum: Economics (pp. 282-284). John Wiley and Sons, Inc.

5. Davis, J., \& Philips, C. (2007). Defensive equity investing: Appealing theory, disappointing reality. Vanguard Investment Counseling and Research, 1-13.

6. Goodspeed, I. (2009). The equity market. South African Institute of Financial Markets.

7. Honkapohja, S. (2009). Financial crisis: Characteristics and crisis management. Astin 2009 Colloquium, Helsink.

8. Kruger, R., Rajaratnam, K., \& Huang, C. (2012). A comparative analysis of aggregational gaussianity for JSE-listed shares and indices. (in review).

9. Levy, H. (1984). Measuring risk and performance over alternative investment horizons. Financial Analysts Journal, 61-68.

10. Mangani, R. (2009). Monetary policy, structural breaks and JSE returns. Investment Analysts Journal, 73, 27-35.

11. Raubenheimer, H. (2012). Managing portfolio managers: The impacts of market concentration, crosssectional return dispersion and restrictions on short sales. (Doctoral dissertation). Stellenbosch: Stellenbosch University.

12. Sassetti, P., \& Tani, M. (2006). Dynamic asset allocation using systematic sector rotation. The Journal of Wealth Management, 8(4), 59-70.

13. Sewell, M. (2011). Characterization of financial time series. Research Note, 1-35.

14. Strugnell, D., Gilbert, E., \& Kruger, R. (2011). Beta, size and value effects on the Johannesburg Stock Exchange. Investment Analyst Journal, 2(74), 1-17.

15. van Rensburg, P. (2002). Market segmentation on the Johannesburg Stock Exchange II. Journal for Studies in Economics and Econometrics, 26(1), 1-19.

16. Ward, M., \& Muller, C. (2012). Empirical testing of the CAPM on the Johannesburg Stock Exchange. Investment Analysts Journal, 76, 1-12.

17. Waxler, C. (2004). Stocking up on sin: How much to crush the market with vice- based investing. John Wiley and Sons Inc.

18. Wooldridge, J. (2009). Part 2: Regression analysis with time series data. In Introductory econometrics: A modern approach 4th edition (pp.377-379). Michigan: South-Western Cengage Learning.

19. Yoon, E. (2012). State of the sector: healthcare. Fidelity viewpoints. Retrieved 2013, May 10 from https://www.fidelity.com/viewpoints/state-of-healthcare-sectors 


\section{$\underline{\text { NOTES }}$}

